\title{
Opening and closing of Oxalis leaves in response to light stimuli
}

\author{
Fumi Nakanishi, Masami Nakazawa and Nobuyasu Katayama \\ Tokyo Gakugei University, Japan
}

\begin{abstract}
Fully opened leaves of potted plants of Oxalis corymbosa DC. closed completely by folding their leaflets downward after being kept in the dark for two hours. The folded leaflets, then moved upward gradually after exposure to light. We developed a simple method to measure the leaf movement. A paper protractor folded every $10^{\circ}$ was devised to measure the opening angles between the stalk and main vein of each leaflet. The greater parts of the lamina of an excised leaf with its stalk were removed to measure the opening angles more correctly. It was confirmed that the processed-excised leaf exhibited the opening-closing movement in response to light stimuli in the same manner as an intact leaf. We investigated the effects of light quality (blue, red and white) on leaf movements with the processed-excised leaf and the paper protractor. It was demonstrated that the processedexcised leaf of $O$. corymbosa is sensitive to blue light, but not to red light. The experiment described in the present paper is appropriate for studying the leaf nastic movement in secondary biology. Key words: Laboratory exercise; Leaf nastic movement; Light stimuli; Oxalis corymbosa; Secondary biology.
\end{abstract}

\section{Introduction}

Among plant movements that occur in response to environmental stimuli, those independent of the direction of stimuli are known as nastic movements. Charles Darwin addressed this exciting biological phenomenon in his book The Power of Movement in Plants based on his own experiments (Darwin, 1880. The full text can be viewed at: http://pages.britishlibrary.net/charles.darwin3/movement/move_fm.htm). Plants belonging to Fabaceae and Oxalidaceae and some other families show diurnal leaf movements, so called nyctinastic or sleeping movements, opening in the light and closing in the dark (Galston and Davies, 1970). These movements are, in principle, controlled by a circadian clock (Bünning, 1973).

In addition, light can directly induce pulvinar bending. Fondeville et al (1967) clearly confirmed that both blue and far-red light most effectively caused the opening response in darkclosed leaflets of Mimosa pudica L. The site of photoreception inducing the opening response in the Mimosa leaflets was determined to be the pulvinus itself (Watanabe and Sibaoka, 1973).

Recently, it has been shown that these movements are regulated by changes in the volume of the motor cells (cortical parenchyma cells) of the pulvinus, a specialised leaf structure, in response to turgor pressure (Mohr and Schopfer, 1995). Evidence has been provided that the diurnal movement controlled by a circadian clock, with or without participation of the photonastic response, is based on ion-channel properties that are distinct between the extensor and the flexor motor cells in Samanea saman (Kim et al, 1992; Moshelion and Moran, 2000). Furthermore, the water channels (aquaporins) in plasma membrane and tonoplast are involved in the osmoregulation of the motor cells of S. saman and M. pudica, respectively (Fleurat-Lessard et al, 1997; Moshelion et al, 2002).

This phenomenon is noteworthy as a subject for biology education. It can be used at primary and secondary levels to study the relation between the physiological aspects of plants and lighting conditions (lino and Takeda, 1988).

Oxalis corymbosa DC. (O. Martiana Zucc.), is native to South America and its leaves exhibit the opening-closing movement in response to light stimuli. It is very common and is available almost throughout the year in Japan. Its fully opened leaves close completely by folding their leaflets downward after being kept in the dark for two hours. The folded leaflets then move upward gradually after exposure to light (Figure 1). To allow high school students to study how environmental factors affect plant growth and development, an experiment to analyse the opening-closing movement of O. corymbosa leaf was devised.

\section{Materials and methods}

\section{Plant and leaf position}

Potted plants of O. corymbosa were grown in a growth cabinet at $25^{\circ} \mathrm{C}$ under a 16-hour photoperiod. Light (ca 6 klux $=54$ $\mu \mathrm{mol} \mathrm{m} \mathrm{m}^{-2} \mathrm{~s}^{-1}$ ) was obtained from fluorescent lamps (FLR40S D/M; Toshiba, Japan).

Fully developed leaves with $10 \mathrm{~cm}$ straight stalks were excised under the light, placed in test tubes $(\phi 10 \mathrm{~mm} \times 75 \mathrm{~mm})$ with the cut ends of stalks deeply immersed in distilled water (Figure 2A), and used for the experiment.

The angle between the stalk and the main vein of each leaflet (leaflet-opening angle) was measured with a hand-made paper 


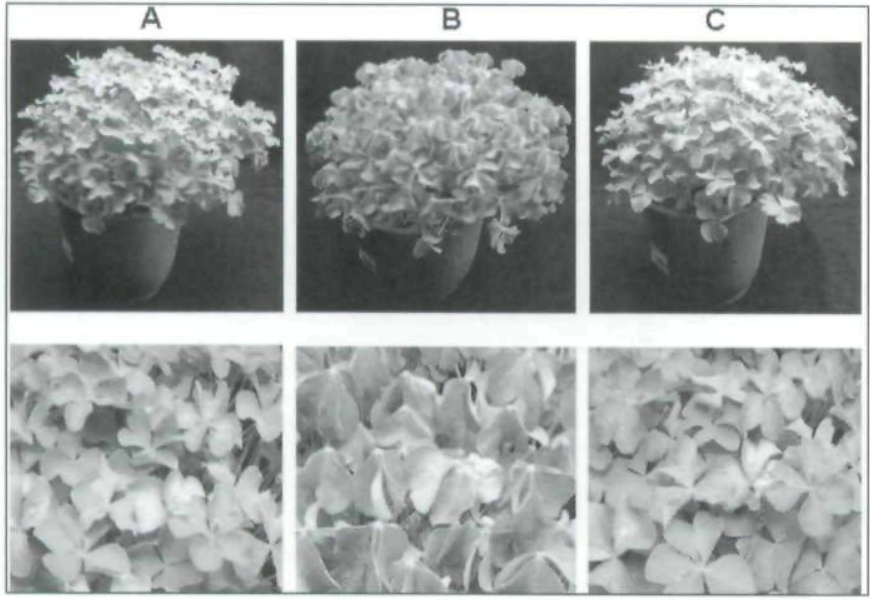

Figure 1. Opening-closing movements in response to light stimuli in leaves of potted plants. Potted plants with fully opened leaves $(A)$ were subjected to a 2-hour dark period (B) and then placed under the light of $32 \mu \mathrm{mol} \mathrm{m} \mathrm{m}^{-2} \mathrm{~s}^{-1}$ for 1 hour (C).

protractor, which was folded every $10^{\circ}$ as shown in Figure 2B. At least four leaves, each with three leaflets, were subjected to each treatment. All experiments were carried out at $25^{\circ} \mathrm{C}$.

\section{Light source}

Fluorescent lamps (FLR40S D/M, Toshiba, Japan) were used for obtaining white light. Red and blue light was obtained by covering the same fluorescent lamps with red and blue coloured cellophane, respectively. The transmission spectra of these coloured cellophanes are shown in Figure 3. The light intensity was determined by a photometer: Memory Sensor MES-101 which can be equipped with the Quantum Sensor IKS-27/101 or the Illuminance Sensor IKS-17/101 (Koito Industries Ltd, Japan).

\section{Results}

An excised leaf attached to its stalk exhibited the opening-closing movement in response to light stimuli in the same manner as an intact leaf. This coincides with the results shown in the report of Engelmann at the website of Tübingen University ${ }^{1}$. Light irradiation for 30-40 minutes was required for noticeable leaf opening (Figure 4). In order to assess the leaf movement quantitatively, we devised a paper protractor. This tool can be folded small in order to adjust to the opening angle between the main vein of a leaflet and the stalk of the excised leaf, and it makes the measurement of the leaflet-opening angle quick and accurate. However, we still found some difficulty in measuring the leaflet-opening angle when the angle was small, because the lamina of leaflets covered the stalk and interfered with the measurement of the angle.
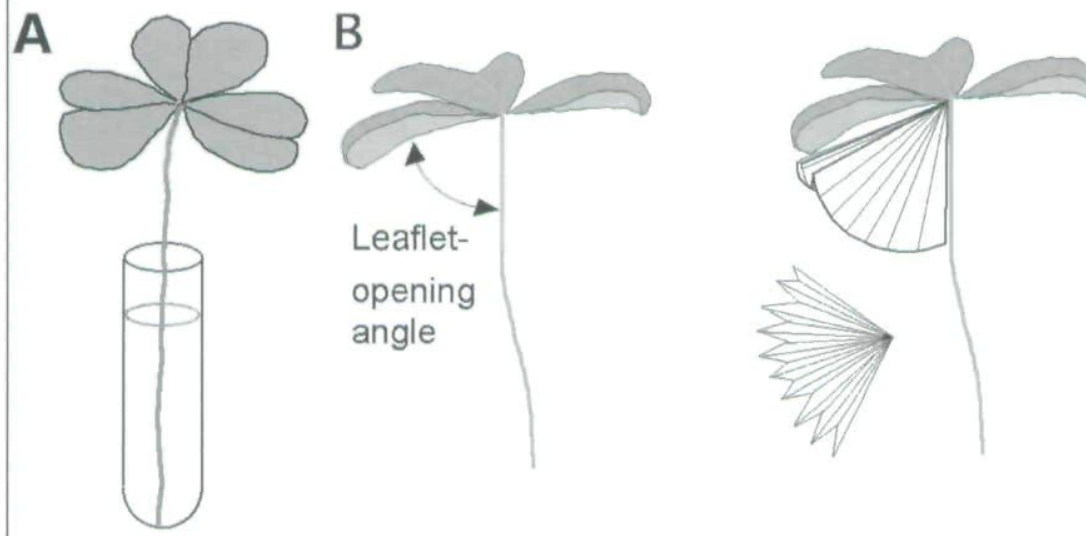

Figure 2 (above). An excised leaf of $\mathrm{O}$. corymbosa with a $10 \mathrm{~cm}$ straight stalk placed in a test tube $(\phi m m \times 75 \mathrm{~mm}$ ) containing distilled water (A) and the method for measuring the leaflet-opening angle (B). The angle between the stalk and the main vein of each leaflet was measured with a hand-made paper protractor.

Figure 3 (below). Spectral transmissivity of red (A) and blue (B) cellophane recorded with a Shimadzu UV-160A spectrophotometer.

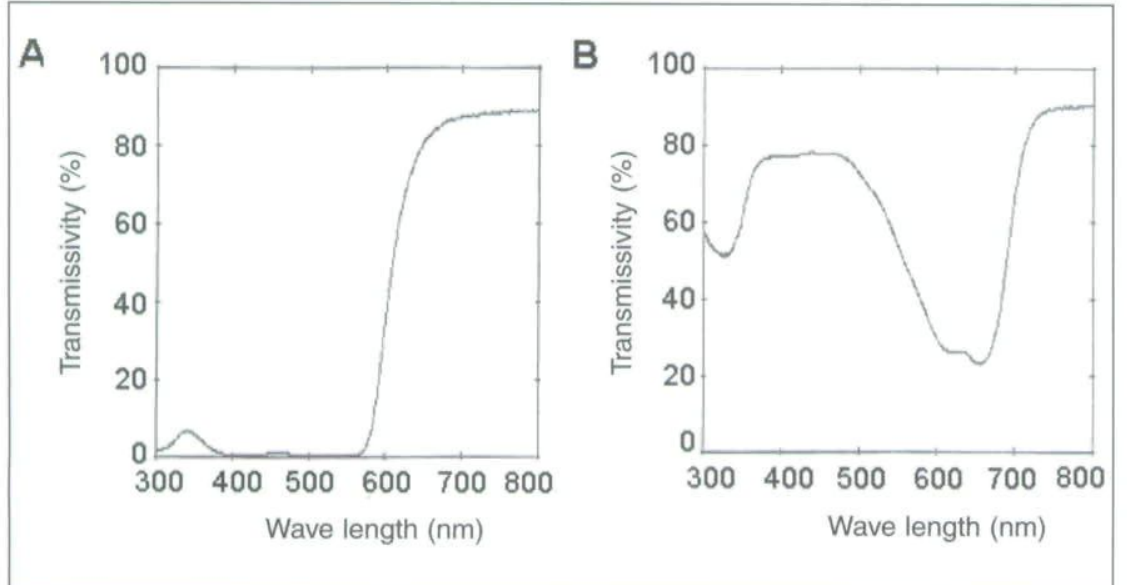

It has been considered that both the reception site of light stimuli and the reaction site are not the lamina, but the pulvinus of the leaflet (Watanabe and Sibaoka, 1973). Therefore, we removed the lamina of excised leaves in various ways (referred to as 'processed-excised leaves'). These processed-excised leaves were subjected to a one-hour dark period. The fully folded leaves were then transferred into the light and leaflet-opening angles were measured periodically. The removal of the lamina of leaflets did not affect the opening movement (Figure 5). The processed-excised leaves, of which the greater parts of the lamina in each leaflet were removed, showed the same leaf-opening response to the light stimuli as those of intact plants (Figure 6).

The sensitivity of the processed-excised leaves and non-processed-excised ones to light stimuli was almost the same for the opening movement; the light intensity required for opening the leaf was less than $0.2 \mu \mathrm{mol} \mathrm{m} \mathrm{m}^{-2} \mathrm{~s}^{-1}$ (Figure 7). Irradiation of the fully opened leaves by low intensity light resulted in leaf closure, the angle being dependent on the light intensity (Figure 8).

Fully folded leaves (prepared by a 90-minute dark period) opened in response to dim blue light $\left(0.13 \mu \mathrm{mol} \mathrm{m} \mathrm{m}^{-2} \mathrm{~s}^{-1}\right)$, but not to a higher intensity $\left(5.6 \mu \mathrm{mol} \mathrm{m} \mathrm{m}^{-2} \mathrm{~s}^{-1}\right)$ of red light (Figure 9). The irradiation of fully opened processed-excised leaves by red light with a lower intensity than

${ }^{1}$ (http://bioclox.bot.biologie.unituebingen.de/Html_we/Buch/ren96/node95.html) 

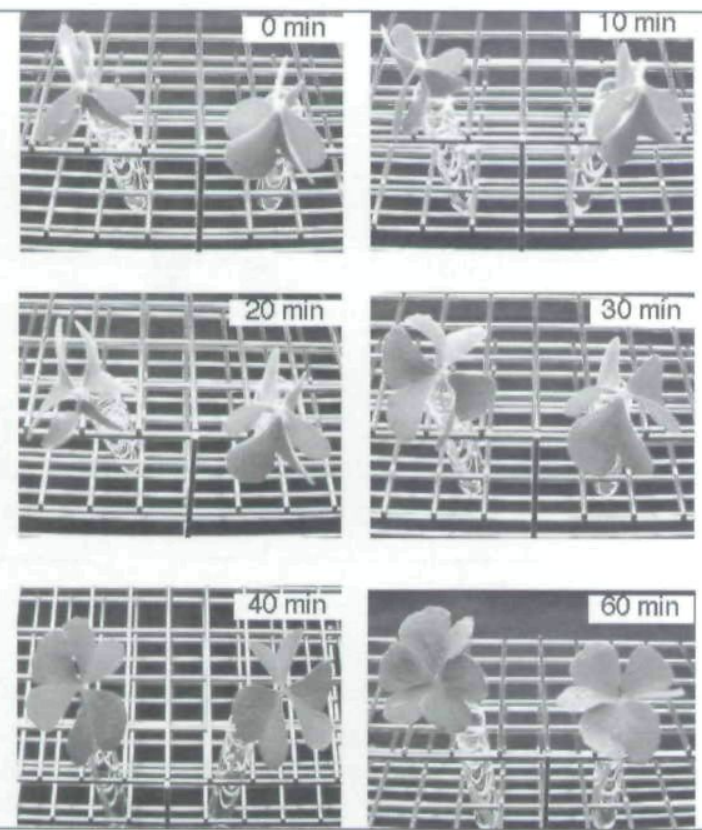

Figure 4. Opening movements in response to light stimuli in excised leaves. Fully opened leaves with 10-cm straight stalks were excised under the light and subjected to 1-hour dark period and then placed under the light of $32 \mu \mathrm{mol}$ $m^{-2} s^{-1}$ at time zero.

$5.6 \mu \mathrm{mol} \mathrm{m}^{-2} \mathrm{~s}^{-1}$ induced the closing movement in the same way as darkness did, but blue light of the same intensity did not do that (Figure 10). We obtained the same results using a blue light-emitting diode (LED) (max. $470 \mathrm{~nm}$ ) and a red LED (max. $670 \mathrm{~nm}$ ) as light sources (data not shown).

\section{Discussion}

From the results obtained in the present study, we consider that the processed-excised leaves can be substituted for intact leaves

Figure 5. Effects of partial removal of lamina on the opening movements in response to light stimuli in excised leaves. Fully opened leaves with 10-cm straight stalks were excised under the light and a part of their lamina was removed in two ways $(B, C)$. Non-processed-excised leaves $(A)$ and processed-excised leaves $(B, C)$ were subjected to a 1-hour dark period, and then, placed under the light of $32 \mu \mathrm{mol} \mathrm{m} \mathrm{m}^{-2} \mathrm{~s}^{-1}$ at time zero. Leaflet-opening angle under the light condition was measured periodically. The mean values $\pm S E$ from 36 leaflets are shown.
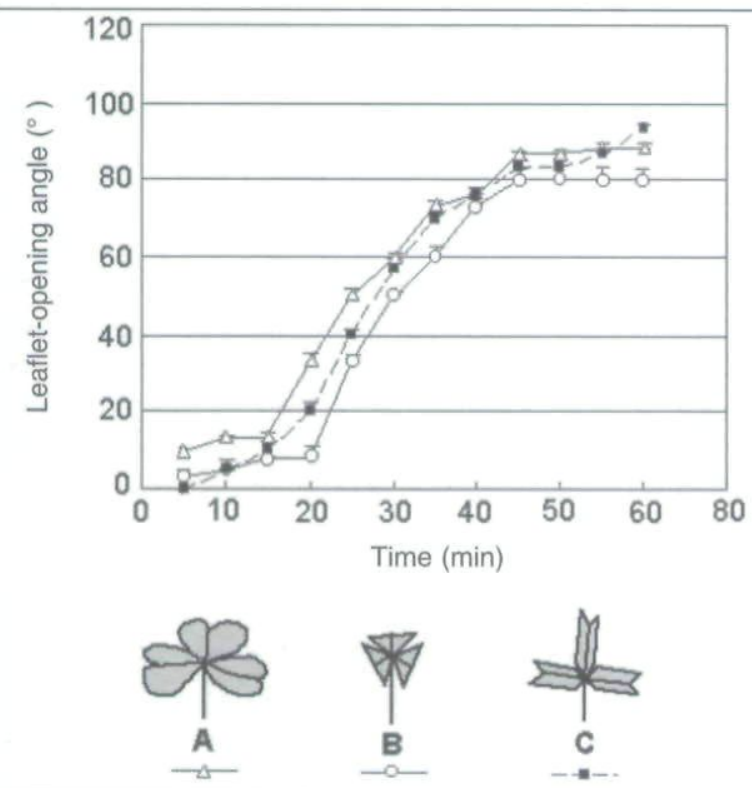
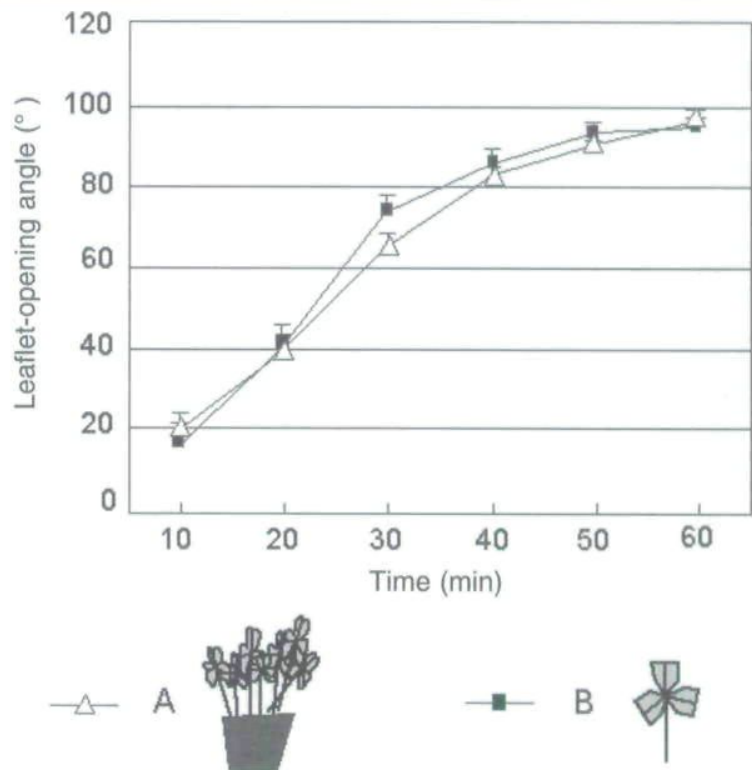

Figure 6. Opening movements in response to light stimuli in processedexcised leaves and intact leaves of potted plants. Potted plants $(A)$ with fully opened intact leaves and fully opened processed-excised leaves (B) were subjected to a 1-hour dark period and then placed under the light of 32 umol $m^{-2} s^{-1}$ at time zero. Leaflet-opening angle under the light condition was meas. ured periodically. The mean values \pm SE from 12 leaflets are shown.

to observe the opening-closing movement in response to light stimuli. These experiments clearly and easily demonstrated that the pulvinus of O. corymbosa leaf perceives blue light, but not red light, as the light stimulus. We carried out our experiments in a darkened room. A cardboard box with a window on which a cover of cardboard or coloured cellophane can be attached may be useful for the dark and light treatments in student laboratory exercises.

Only a small number of laboratory exercises on 'plant growth and development' have been devised for secondary biology (e.g.

Figure 7. Light dose-response curve of opening movements in processedexcised leaves. Completely folded non-processed- (A) and processed- (B) excised leaves, which had been subjected to a 90 minute dark period, were placed under light of different intensities. The leaflet-opening angle was measured $30 \mathrm{~min}$ after starting light irradiation. The mean values $\pm S E$ from 24 leaflets are shown.

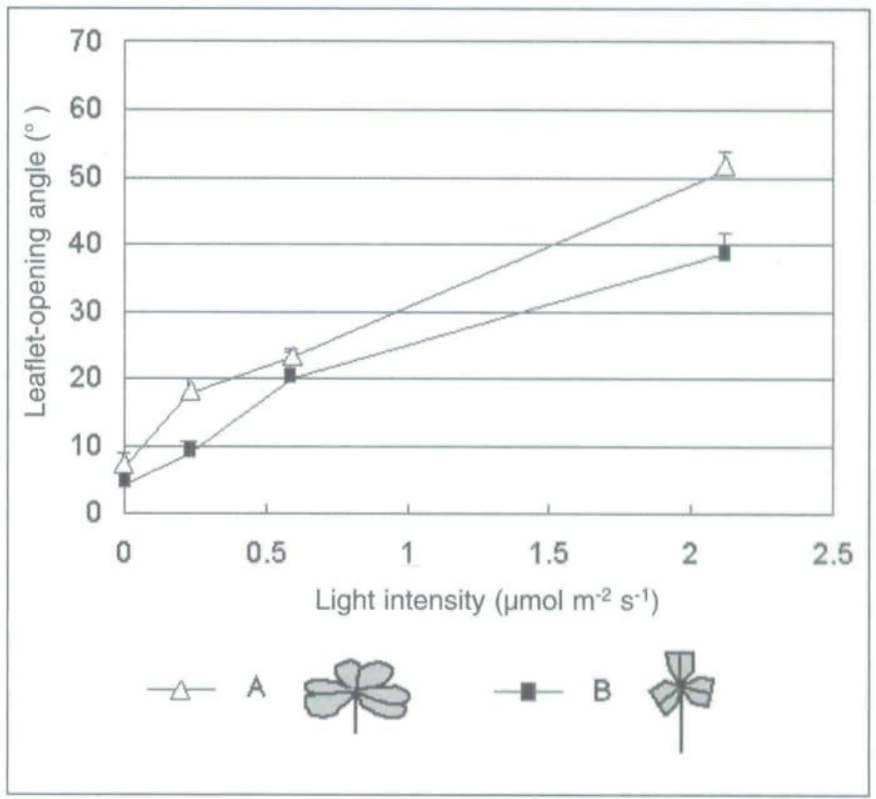




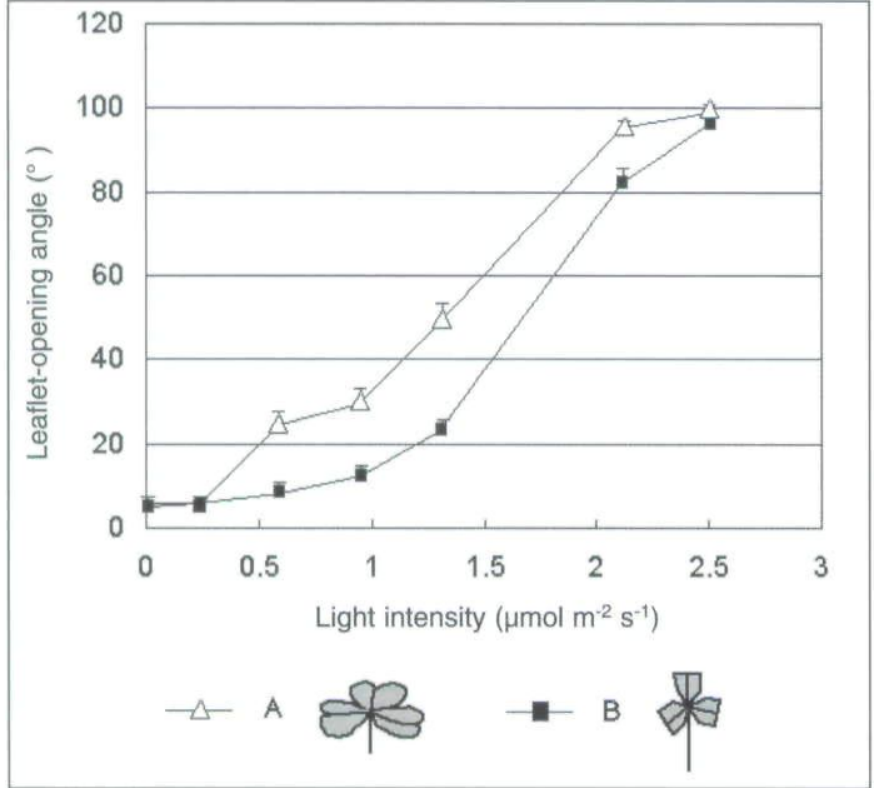

Figure 8. Responses of fully opened leaves to dim light of different intensities. Fully opened non-processed-and processed-excised leaves were placed under light of different intensities for $90 \mathrm{~min}$. The mean values $\pm S E$ from 24 leaflets are shown.

Hannay, 1967; Iino and Takada, 1988). Most of them cannot be finished in 'one school hour' (50 minutes). By using the processed-excised leaves of $\mathrm{O}$. corymbosa and the paper protractor devised in the present study, the measurement of the opening angle between the stalk and the main vein of each leaflet is made quick and accurate. The leaf opening movement in nastic response to light stimuli can be observed and determined quantitatively within one school hour. On the other hand, though the observation and quantitative measurement of leaf closing movement cannot be done periodically, it may be possible to observe and measure the leaf closing at least 30 minutes after transferring fully opened leaves into the dark. In addition, students can examine certain kinds of environmental conditions (light intensity, light quality, and so on) at the same time. Thus, the experiment developed in the present study seems more appropriate than that developed by Iino and Takeda (1988)

Figure 9. The effects of light quality on opening movements of processed-excised leaves. Completely folded processed-excised leaves, which had been subjected to a 90 minute dark period, were placed under blue light and red light of different intensities. The leaflet-opening angle was measured 30 minutes after starting light irradiation. The mean values \pm SE from 36 leaflets are shown.

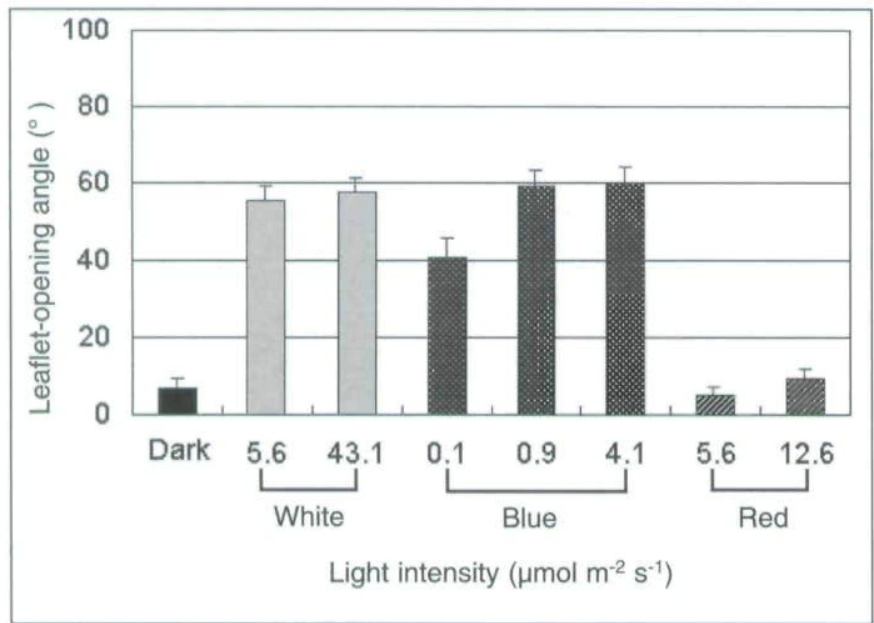

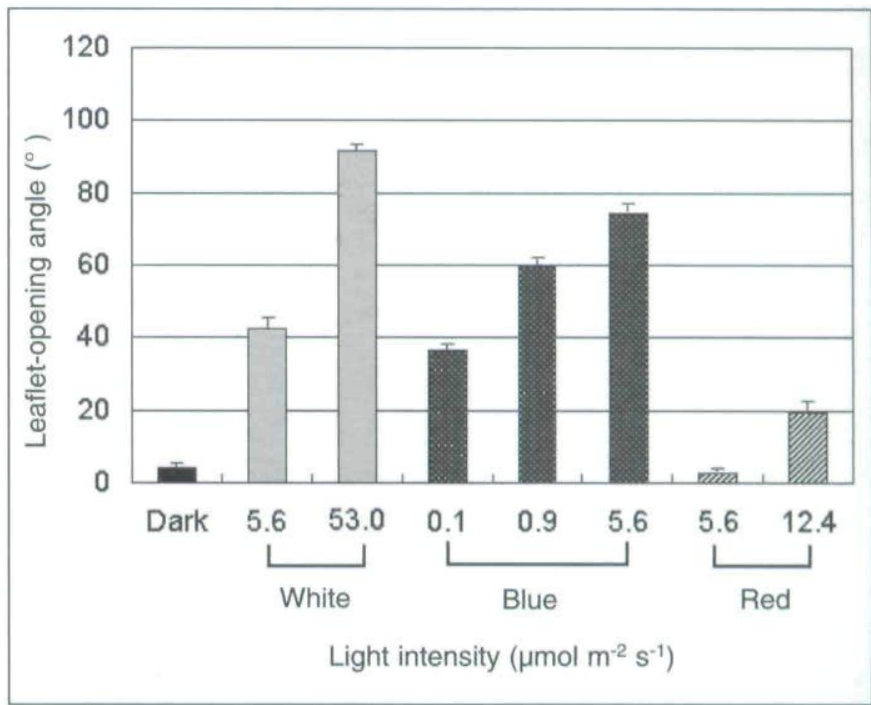

Figure 10. Responses of fully opened leaves to blue light and red light. Fully opened processed-excised leaves were placed under different light conditions for 90 minutes, and then the leaflet-opening angle was measured. The mean values $\pm S E$ from 36 leaflets are shown.

When studying the responses in organisms to light stimuli, it is very important for students to understand the relation between the light-perceiving site and action site and the dependence of the response on light quality. By using O. corymbosa leaves, from which the lamina of the leaflets is removed, students can notice that the light-perceiving site for this phenomenon might be the pulvinus of leaflets. With some additional instructions by the teacher, students can understand that the pulvinus regulates the turgor pressure of its cells in the photonastic movement. At the advanced level, students can notice through the experiment that the photonastic movement is caused by blue light but not by red light, which indicates that one or more particular photoreceptors participate in this phenomenon.

Teachers can use equipment such as a digital camera or a time-lapse video camera to record the leaf opening movement in photonastic response; recording the closing leaf movement is only possible under dim red light. Although such kinds of recorded material allow students to observe the phenomenon in detail and repeatedly, it seems better for students to carry out an exercise using the actual organism because handling real organisms enhances students' interest in learning biology. For example, students might be surprised when they try to lift Oxalis folded leaflets up; it is very hard to do so without injuring the leaflets.

The opening-closing movements in diurnal movement have been studied intensively for O. regnellii (Skrove et al, 1982; Pedersen et al, 1993), but this plant is still unfamiliar in Japan. O. corymbosa is not native to Japan; the plant might have been imported as a garden herb, but now it is very common as a weed in gardens and on roadsides. As students are very familiar with this plant and the leaves of this plant are obtainable almost throughout the year, the exercise can be carried out whenever teacher or students want. About 800 species are known in the genus Oxalis, occurring in various parts of the world as wild herbs. Some of them are cultivated as garden plants. Most of them exhibit the opening-closing movement in response to light stimuli and seem to be useful as materials for the exercise. In Northern and Western Europe and the British Isles, wood-sorrel (O. acetosella) might substitute for O. corymbosa (Rose, 1981). Some oxalis 
common for gardeners such as O. regnellii, O. deppei and O. adenophylla are obtainable at gardening shops or through the Internet.

\section{Acknowledgement}

This work was supported by a Grant-in-Aid for Science Research from the Ministry of Education, Culture, Sports, Science and Technology.

\section{References}

Bünning E (1973) The Physiological Clock, Third Edition, Academic Press, New York.

Darwin C (1880) The Power of Movement in Plants, John Murray, London.

Fleurat-Lessard P, Frangne N, Maeshima M, Ratajczak R, Bonnemain J L and Martinoia E (1997) Increased expression of vacuolar aquaporin and $\mathrm{H}^{+}$-ATPase related to motor cell function in Mimosa pudica L. Plant Physiology 114, 827-834.

Fondeville J C, Schneider M J, Borthwick H A and Hendricks S B (1967) Photocontrol of Mimosa pudica L. leaf movement. Planta 75, 228-238.

Galston A W and Davies P J (1970) Control Mechanisms in Plant Development. Prentice-Hall, Inc, Englewood Cliffs, New Jersey.

Hannay J W (1967) Light and seed germination - an experimental approach to photobiology. Journal of Biological Education 1, 65-73.

lino A and Takeda K (1988) Studies on the leaflet movement of Mimosa pudica as teaching materials of red - far red photo-reversible reaction in plants. Journal of Science Education in Japan 12, 98-103.

Kim H Y, Coté G G and Crain R C (1992) Effects of light on the membrane potential of protoplasts from Samanea saman pulvini. Plant Physiology 99, 1532-1539.

Mohr H and Schopfer P (1995) Plant Physiology (English version), Springer-Verlag, New York.

Moshelion M and Moran N (2000) Potassium-efflux channels in extensor and flexor of the motor organ of Samanea saman are not identical. Effects of cytosolic calcium. Plant Physiology 124, 911-919

Moshelion M, Becker D, Biela A, Uehlein N, Hedrich R, Otto B, Levi H, Moran N and Kaldenhoff R (2002) Plasma membrane aquaporins in the motor cells of Samanea saman: diurnal and circadian regulation. The Plant Cell 14, 727-739.

Pedersen M, Johnsson A, Mæhle J and Dallækken R (1993) Short period leaf movements in Oxalis regnellii. Physiologia Plantarum 89, 277-284.

Rose F (1981) The Wild Flower Key. Frederick Warne, Ltd., London.

Skrove E, Rinnan T and Johnsson A (1982) Effect of abscisic acid on the circadian leaf movements of Oxalis regnellii. Physiologia Plantarum $55,221-225$.

Watanabe S and Sibaoka T (1973) Site of photo-reception to opening response in Mimosa leaflets. Plant and Cell Physiology 14, 1221-1224.

\section{Appendix}

\section{Suppliers}

Sheets of coloured cellophane (blue and red) for light filters are available at craft shops, artist shops, or through the Internet (e.g. www.schoolsurplus.co.uk; www.specialistcrafts.co.uk/; www.homecrafts.co.uk).

A handy light sensor meter, Memory Sensor MES-101, used in the present study is a product of Koito Industries, Ltd (Koito
Industries, Ltd. Takanawa, Minato-ku, Tokyo 108-8723, Japan. Tel: + 81-3-3443-9846. Fax: + 81-3-3443-6570; Email: info@koito-ind.co.jp; Website: www.mmjp.or.jp/koito-environ/LightSensor.html, the site is only Japanese). The device can be connected with the light sensors IKS-27/101 and IKS$17 / 101$ to measure the photon flux density (PFD) and the illuminance, respectively.

\section{Light intensity conversion}

Few secondary schools have light meters (quantum-meters) which can measure photon flux density. On the other hand, many schools have illuminometers which are generally cheaper than any quantum-meter and can be purchased easily anywhere, e.g., at a camera shop. You also may use the Light SensorMeter (Cat. No. COH27659) provided by Philip Harris (Philip Harris Education, Novara House, Excelsior Road, Ashby Park, Ashby de la Zouch, Leicestershire, LE65 1NG, UK. Tel: + 44 (0)870 6000 193; Fax: + 44-(0)800 731 0003; Email: sales@education.philipharris.co.uk; Website: www.philipharris.co.uk). Therefore, in the present paper we show light intensities in both PFD and illuminance for the convenience of teachers to convert the illuminance to PFD. However, the factor for conversion is not constant; it is dependent on the light colour as well as light source. For example, in the case of the fluorescent lamp we used in the present study, 1 klux of direct light from the lamp equals $9 \mu \mathrm{mol} \mathrm{m}{ }^{-2} \mathrm{~s}^{-1}$. For light from the same fluorescent lamp covered with a blue cellophane sheet or a red cellophane sheet, 1 klux equals $8 \mu \mathrm{mol} \mathrm{m}{ }^{-2} \mathrm{~s}^{-1}$ and $36.5 \mu \mathrm{mol} \mathrm{m} \mathrm{m}^{-2} \mathrm{~s}^{-1}$, respectively. In the case of light from a projector lamp (Phillips FP-10S, 100V, $300 \mathrm{~W}$ ), 1 klux equals $18.5 \mu \mathrm{mol} \mathrm{m} \mathrm{m}^{-2} \mathrm{~s}^{-1}$. Any illuminometer has its most sensitive spectrum-band at around $550 \mathrm{~nm}$.

\section{Websites}

http://pages.britishlibrary.net/charles.darwin3/movement/move_fm.htm Full text of 'The Power of Movement in Plants' can be seen at this site. http://bioclox.bot.biologie.uni-tuebingen.de/Html_we/Buch/ren96/node95.html

Some important information about the leaf movement of Oxalis regnellii is provided by Engelmann, W:

www.topekahomefinder.com/stories/032203/hom_sell.shtml Brief explanation of nasties by Sell, P. in his column 'Plant movements are colorfully named' at this site.

Fumi Nakanishi is a lecturer in the Department of Biology, Tokyo Gakugei University. Masami Nakazawa is currently a teacher at Oizumigakuen-Sakura Elementary School. At the time of the present study, he was an undergraduate student of Tokyo Gakugei University. Nobuyasu Katayama (corresponding author) is a professor in the Department of Environmental Sciences, Tokyo Gakugei University, Koganei, Tokyo 184-8501, Japan. Contact details for Nobuyasu Katayama - Tel: + 81-42329-7518. Fax: + 81-42-329-7737. Email:katayama@u-gakugei.ac.jp 
Copyright of Journal of Biological Education is the property of Institute of Biology and its content may not be copied or emailed to multiple sites or posted to a listserv without the copyright holder's express written permission. However, users may print, download, or email articles for individual use. 